\title{
Biochemical profile of two ethnically edible ectomycorrhizal mushrooms of southwest India
}

\author{
Greeshma AA ${ }^{1}$, Anu-Appaiah KA ${ }^{2}$, Pavithra $M^{1}$ and Sridhar $K_{R}{ }^{1,3^{*}}$ \\ ${ }^{1}$ Department of Biosciences, Mangalore University, Mangalagangotri, Mangalore, Karnataka, India \\ ${ }^{2}$ Department of Food Microbiology and Fermentation Technology, Council of Scientific and Industrial Research - \\ ${ }^{3}$ Centre for Environmental Studies, Yenepoya (Deemed to be University), Mangalore, Karnataka, India
}

Greeshma AA, Anu-Appaiah KA, Pavithra M, Sridhar KR 2021 - Biochemical profile of two ectomycorrhizal edible mushrooms of the Western Ghats. Fungal Biotec 1(2), 39-49, Doi 10.5943/FunBiotec/1/2/3

\begin{abstract}
Edible mushrooms constitute the best natural source of bioactive compounds as well as antioxidants. Two edible ectomycorrhizal mushrooms of the Western Ghats of India (Amanita sp. and Astraeus hygrometricus) assessed for the biochemical profile. Aqueous extracts of dried powders of uncooked and cooked fruit bodies of mushrooms were evaluated for their soluble sugars and organic acids, while the methanol extract was used to detect polyphenols. Profiles of soluble sugars, organic acids, and polyphenols differed between the mushrooms as well as uncooked and cooked samples. Uncooked samples of both mushrooms possess higher quantities of sugars, organic acids, and polyphenols. Fructose is a common sugar in uncooked and cooked mushrooms, as well as tartaric acid, myricetin, and ethyl catechol. Trehalose was detectable only in Amanita, which has several industrial applications. Ascorbic acid found in both mushrooms and it is useful as a nutraceutical. Myricetin found in substantial quantities in both mushrooms, which serve as a nutraceutical owing to its antioxidant potential. The p-coumaric acid found in uncooked samples of both mushrooms. The novelty of these uncooked and cooked mushrooms in nutrition and bioactive potential will pave the way to adapt them for the human diet as well as in the production of healthpromoting functional foods.
\end{abstract}

Keywords - Amanita-Astraeus - ectomycorrhizae - organic acids - polyphenols - sugars

\section{Introduction}

Mushrooms constitute a potential source of bioactive compounds of nutritional, health, and nutraceutical significance worldwide (Hobbs 2000, Cheung 2010, Chang \& Wasser 2012). They became a popular dietary source due to their high levels of nutrients (carbohydrates, fiber, proteins, and vitamins) and low levels of fat and calories. In addition, mushrooms possess therapeutics like antioxidants, antimicrobials, antitumor, and immunomodulators substances that potentially useful in the production of value-added functional foods.

Edible ectomycorrhizal mushrooms have tripartite functions such as root symbionts with tree species facilitate drawing nutrients from the soil, and several of them are medicinally as well as nutritionally versatile. Many edible ectomycorrhizal mushrooms possess nutraceutical significance (e.g. Canterelles, milk caps, porcini, truffles, and Russula). There are up to 1,100 edible ectomycorrhizal mushrooms that possess medicinal, nutritional, and ethnic economic significance (Hall et al. 2011, Boa 2012, Zambonelli \& Bonito 2012, Pérez-Moreno \& Martínez-Reyes 2014, 
Hyde et al. 2019). Comparison of the number of species of edible ectomycorrhizal mushrooms in 15 genera performed with the WUFbase (Wild Useful Fungi database) (Boa 2004, Hall et al. 2011). Among them, Russula was first (72-110 species) followed by Lactarius (58-84 species). The maximum number of edible ectomycorrhizal mushrooms are sold in Mexico (77 species) followed by Nepal (13 species) (Boa 2004). Cultivation of ectomycorrhizal mushrooms is a challenge without the specific host tree (Hall et al. 2003). However, if it is possible to generate substantial biomass of mycelia of ectomycorrhizal fungi on agro-wastes, the possibilities are fair for fetching the health-promoting sugars, organic acids, and polyphenols.

The Western Ghats and west coast of India are endowed with several wild edible, medicinal and ectomycorrhizal mushrooms (Farook \& Manimohan 2013, Karun \& Sridhar 2013, Senthilarasu 2014, Senthilarasu \& Kumaresan 2016, Pavithra et al. 2015, 2016a, 2016b, Karun \& Sridhar 2014, 2016, 2017, Latha \& Manimohan 2017, Sridhar \& Karun 2019). The species richness of ectomycorrhizal species of Inocybe is the highest followed by Amanita and Russula. Interestingly, tree species belonging to the family Dipterocarpaceae also follow the same pattern of species richness. Although, Amanita generally regarded as poisonous, among the 15 edible ectomycorrhizal mushroom genera, Amanita positions in fourth place with 55 species (Hall et al. 2011).

While surveying the wild edible mushrooms of India's Western Ghats and southwest region, an Amanita sp. discovered in the lateritic scrub jungles and consumed by the local community at a tender stage (Karun \& Sridhar 2014). Meticulous observations revealed that this Amanita sp. is ectomycorrhizal with many tree species in scrub jungles (e.g. Acacia auriculiformis, A. mangium, Anacardium occidentale, Hopea ponga, and Terminalia paniculata). Astraeus hygrometricus found in the foothills of the Western Ghats (Pavithra et al.2015). It was associated with many tree species (e.g. Artocarpus hirsutus, Holigarna arnottiana, Hopea parviflora, H. ponga, Phyllanthus emblica, and Syzygium cumini). A series of studies have been carried out on the edibility and medicinal attributes of uncooked and cooked Amanita sp. (Greeshma et al. 2018a, 2018b, 2018c) as well as Astraeus hygrometricus (Pavithra et al. 2017, 2018). However, there is a knowledge gap on the biochemical profile and the pattern of ectomycorrhizal association of these mushrooms.

The organoleptic qualities (aroma, flavour, and taste) of mushrooms are dependent on the soluble sugars and organic acids. Soluble sugars are valued since they have therapeutic significance, while the organic acids possess radical scavenging, antimicrobial, anti-inflammatory, and neuroprotective attributes (Yoon et al. 2011, Barros et al. 2013, Leal et al. 2013). Similar to soluble sugars and organic acids, polyphenols present in mushrooms serve as potential antioxidants to quench free radicals (Cheung et al. 2003, Valentão et al. 2005a, Gąsecka et al. 2018). The current study envisaged assessing the soluble sugars, organic acids, and polyphenols of uncooked and cooked Amanita sp. and Astraeus hygrometricus obtained from the lateritic scrub jungles of southwest India and foothills of the Western Ghats of India, respectively.

\section{Materials \& Methods \\ Mushrooms and process}

Tender sporocarps of ectomycorrhizal Amanita sp. were collected from the basins of Anacardium occidentale trees in the scrub jungles on the outskirts of Mangalore, India $\left(12^{\circ} 48^{\prime} \mathrm{N}-74^{\circ} 55^{\prime} \mathrm{E}, 100-115 \mathrm{~m}\right.$ asl). Tender sporocarps of another ectomycorrhizal mushroom, Astraeus hygrometricus (Pers.) Morgan, were collected from the Karkala forests of the foothills of the Western Ghats of India $\left(13^{\circ} 12^{\prime} \mathrm{N}-74^{\circ} 58^{\prime} \mathrm{E} ; 67-90 \mathrm{~m}\right.$ asl). Mushrooms collected from three locations about 50-150 meters apart, rinsed separately in distilled water to eliminate soil, roots, and dirt. Cleaned sporocarps spread on a paper towel and blotted to remove the surface moisture. Divided each sample into two groups. The first group was oven-dried $\left(55 \pm 2{ }^{\circ} \mathrm{C}\right)$, while the second was pressure-cooked with distilled water $(1: 0.25 \mathrm{v} / \mathrm{v})$ followed by oven drying $\left(55 \pm 2^{\circ} \mathrm{C}\right)$. Continued drying of samples until the moisture content attain below $10 \%$. Powdered dried sporocarps (in Wiley Mill, Thomas ${ }^{\circledR}$, U.S.A.) transferred into airtight containers and refrigerated. 


\section{Extraction}

Sonicated each sample of mushroom flour $(1 \mathrm{~g})$ in distilled water $(5 \mathrm{ml})$ at an amplitude of $40 \%$ and centrifuged $(10,000 \mathrm{rpm}, 15 \mathrm{~min})$. The supernatant concentrated in a vacuum concentrator before diluting to one $\mathrm{ml}$ with Millipore water. These aqueous extracts used for the determination of sugar and organic acid profiles. Followed the same procedure to determine the polyphenol profile with methanol for extraction instead of Millipore water.

\section{Soluble sugars profile}

Concentrated aqueous extract of each sample was filtered through a $0.45 \mu \mathrm{m}$ PTEF (Polytetrafluoroethylene) membrane before assessing the soluble sugars using the HPLC (Shimadzu LC 10 A, Japan) coupled with a refractive index detector (Shimadzu RID-10A). Analysis carried out using the amino column (Kromasil $\mathrm{NH}_{2}, 250 \mathrm{~mm} \times 4.6 \mathrm{~mm}$, particle size 5 $\mu \mathrm{m})$ using acetonitrile-water $(75: 25, \mathrm{v} / \mathrm{v})$ as the mobile phase with a flow rate of $1 \mathrm{ml} / \mathrm{min}$. Sugars identified based on a comparison of the retention time of the peak with the known concentration of standards.

\section{Organic acids profile}

The aqueous extract of samples was analysed for organic acids using the HPLC (Shimadzu LC 10 A, Japan) coupled with a UV detector. The analysis was performed using a reverse-phase C18 column (Intekchromasol RP-C18, $250 \mathrm{~mm} \times 4.6 \mathrm{~mm}$, particle size, $5 \mu \mathrm{m}$ ), injection volume was $5 \mu \mathrm{l}$, and detection at $210 \mathrm{~nm}$. The mobile phase employed was $0.008 \mathrm{M}$ sulphuric acid, at a flow rate of $1 \mathrm{ml} / \mathrm{min}$ in an isocratic mode of elution. Identified the organic compounds based on comparison of the retention time of the peak in comparison with known concentrations of standards.

\section{Polyphenols profile}

The methanol extract filtered through a $0.45 \mu \mathrm{m}$ PTEF membrane onto the subject for polyphenol profile using the HPLC (Shimadzu LC 10 A, Japan). The analysis was performed by the RP C-18 column (Kinetex Reversed-Phase C18, $250 \mathrm{~mm} \times 4.6 \mathrm{~mm}$, particle size $5 \mu \mathrm{m}$ ) coupled with a PDA detector (Shimadzu SPD M20A). The injection volume was $5 \mu 1$, followed by the detection in the range of $280-320 \mathrm{~nm}$. The mobile phases employed were A (100\% acetonitrile) and B (0.1\% o-phosphoric acid). The gradient programme equilibrated until $60 \mathrm{~min}$, at a flow rate of 1 $\mathrm{ml} / \mathrm{min}$ (Table 1). Polyphenols identified by comparing the retention time of the peak of samples examined with that of known concentrations of standards.

Table 1. The program followed for mushroom polyphenol determination using mobile phases A and $\mathrm{B}$ in HPLC.

\begin{tabular}{ccc}
\hline Minutes & Mobile phase A $\mathbf{( m l )}$ & Mobile phase B $(\mathbf{m l})$ \\
\hline 0 & 8 & 92 \\
15 & 8 & 92 \\
30 & 22 & 78 \\
45 & 78 & 22 \\
55 & 8 & 92 \\
60 & 8 & 92 \\
\hline
\end{tabular}

\section{Statistical analysis}

The $t$-test was followed to find the variation in sugars, organic acids and polyphenols between uncooked and cooked mushroom samples based on Statistica Version \# 8.0 (StatSoft 2008).

\section{Results \\ Soluble sugars}

The soluble sugar profile revealed the occurrence of three and five sugars in Amanita sp. and 
Astraeus hygrometricus, respectively (Table 2). The quantity of glucose, fructose, and trehalose was higher in uncooked than cooked Amanita sp. with a significant difference only in glucose content ( $\mathrm{p}<0.001$ ). In Astraeus hygrometricus, galactose, and maltose contents were significantly higher in uncooked samples $(p<1.001)$, while it was the opposite for fructose content $(p<0.001)$. The total soluble sugars were highest in uncooked samples of Amanita sp. $(15.2 \mathrm{mg} / \mathrm{g})$.

Table 2. Soluble sugar profile of aqueous extract of uncooked, and cooked Amanita sp. and Astraeus hygrometricus $(\mathrm{mg} / \mathrm{g})\left(\mathrm{n}=3\right.$, mean $\pm \mathrm{SD} ;{ }^{*}, \mathrm{p}<0.001 ; \mathrm{BDL}$, below detectable limit).

\begin{tabular}{lcccc}
\hline Soluble sugar & \multicolumn{2}{c}{ Amanita sp. } & \multicolumn{2}{c}{ Astraeus hygrometricus } \\
\cline { 2 - 5 } & Uncooked & Cooked & Uncooked & Cooked \\
\hline Glucose & $5.47 \pm 0.25^{*}$ & $0.14 \pm 0.03$ & BDL & BDL \\
Fructose & $0.51 \pm 0.03$ & $0.48 \pm 0.02$ & $0.15 \pm 0.002$ & $0.44 \pm 0.01^{*}$ \\
Galactose & BDL & BDL & $9.47 \pm 0.16^{*}$ & $2.47 \pm 0.03$ \\
Rhamnose & BDL & BDL & $0.49 \pm 0.01$ & $0.35 \pm 0.004$ \\
Sucrose & BDL & BDL & $0.38 \pm 0.01$ & $0.19 \pm 0.002$ \\
Maltose & BDL & BDL & $3.16 \pm 0.1^{*}$ & $0.45 \pm 0.01$ \\
Trehalose & $9.2 \pm 0.26$ & $8.83 \pm 0.4$ & BDL & BDL \\
Total & 15.2 & 9.5 & 13.7 & 3.9 \\
\hline
\end{tabular}

\section{Organic acids}

Altogether, six organic acids recovered from Amanita sp. and Astraeus hygrometricus (Table 3). In Amanita sp., uncooked samples consist of a higher number of organic acids than cooked samples (6 vs. 2), while in Astraeus hygrometricus three organic acids are common in uncooked and cooked samples. Tartaric acid was the highest in uncooked Amanita sp. followed by succinic and malic acids. Tartaric acid in cooked samples of Amanita sp. was significantly higher than in the cooked samples $(\mathrm{p}<0.001)$. In Astraeus hygrometricus, succinic acid was highest, followed by tartaric and ascorbic acids in uncooked as well as cooked samples. Tartaric $(\mathrm{p}<0.01)$ and ascorbic $(\mathrm{p}<0.05)$ acids were significantly higher in uncooked samples of A. hygrometricus, whereas succinic acid $(\mathrm{p}<0.001)$ was significantly higher in cooked than in uncooked samples. The total organic acids were highest in cooked samples of A. hygrometricus $(25.9 \mathrm{mg} / \mathrm{g})$.

Table 3. Organic acid profile of aqueous extract of uncooked, and cooked Amanita sp. and Astraeus hygrometricus $(\mathrm{mg} / \mathrm{g})\left(\mathrm{n}=3\right.$, mean $\pm \mathrm{SD} ; *, \mathrm{p}<0.05 ;{ }^{* *}, \mathrm{p}<0.01, * * *, \mathrm{p}<0.001$; BDL, below detectable limit).

\begin{tabular}{lcccc}
\hline Organic acid & \multicolumn{2}{c}{ Amanita sp. } & \multicolumn{2}{c}{ Astraeus hygrometricus } \\
\cline { 2 - 5 } & Uncooked & Cooked & Uncooked & Cooked \\
\hline Tartaric acid & $6.36 \pm 0.37^{* * *}$ & $0.65 \pm 0.1$ & $2.87 \pm 0.2^{* *}$ & $0.25 \pm 0.02$ \\
Succinic acid & $4.73 \pm 0.15$ & BDL & $5.00 \pm 0.34$ & $25.45 \pm 2.04^{* *}$ \\
Ascorbic acid & $0.05 \pm 0.002$ & BDL & $0.21 \pm 0.01^{*}$ & $0.16 \pm 0.01$ \\
Malic acid & $3.20 \pm 0.15$ & $1.50 \pm 0.2$ & BDL & BDL \\
Pyruvic acid & $0.42 \pm 0.03$ & BDL & BDL & BDL \\
Citric acid & $1.46 \pm 0.04$ & BDL & BDL & BDL \\
Total & 16.2 & 2.2 & 8.1 & 25.9 \\
\hline
\end{tabular}

\section{Polyphenols}

Overall, 11 polyphenols were recovered from Amanita sp. and Astraeus hygrometricus (Table 4). The number of polyphenols was higher in uncooked than cooked samples of Amanita sp. (8 vs. 4) as well as Astraeus hygrometricus (7 vs. 6). In uncooked Amanita samples, the syringic acid content was highest, followed by gallic acid, myricetin, t-cinnamic acid, and epicatechin. Contents of gallic acid $(\mathrm{p}<0.001)$, ethyl catechol $(\mathrm{p}<0.01)$, and $\mathrm{p}$-coumaric acid $(\mathrm{p}<0.01)$ were significantly higher in uncooked samples of Amanita sp. compared to cooked samples. In uncooked Astraeus hygrometricus, the vanillin content was highest followed by myricetin and ethyl catechol, while in 
cooked samples, the epicatechin content was highest followed by myricetin and ethyl catechol. Contents of myricetin $(\mathrm{p}<0.01)$, ethyl catechol $(\mathrm{p}<0.01)$, and vanillin $(\mathrm{p}<0.001)$ were significantly higher in uncooked than cooked samples of A. hygrometricus.

Table 4. Polyphenols in methanol extract of uncooked, and cooked Amanita sp. and Astraeus hygrometricus $(\mu \mathrm{g} / \mathrm{g})(\mathrm{n}=3$, mean $\pm \mathrm{SD} ; *, \mathrm{p}<0.01 ; * *, \mathrm{p}<0.001 ; \mathrm{BDL}$, below detectable limit $)$.

\begin{tabular}{lcccc}
\hline Polyphenols & \multicolumn{2}{c}{ Amanita sp. } & \multicolumn{2}{c}{ Astraeus hygrometricus } \\
\cline { 2 - 5 } & Uncooked & Cooked & Uncooked & Cooked \\
\hline Gallic acid & $10.30 \pm 0.11^{* *}$ & $6.06 \pm 0.32$ & BDL & $1.10 \pm 0.00$ \\
Kaempferol & BDL & BDL & $4.00 \pm 0.0$ & BDL \\
Methyl catechol & $2.10 \pm 0.05$ & BDL & BDL & $0.02 \pm 0.00$ \\
Myricetin & $9.36 \pm 0.25$ & $6.66 \pm 0.2$ & $100 \pm 0.01^{*}$ & $32.00 \pm 0.003$ \\
Ethyl catechol & $6.70 \pm 0.36^{*}$ & $3.33 \pm 0.11$ & $41.00 \pm 0.003^{*}$ & $8 \pm 0.001$ \\
Epicatechin & $6.90 \pm 0.41$ & BDL & BDL & $220 \pm 0.002$ \\
t-Cinnamic acid & $8.28 \pm 0.16$ & BDL & $1.30 \pm 0.0$ & BDL \\
Chlorogenic acid & BDL & BDL & $1.30 \pm 0.0$ & BDL \\
p-Coumaric acid & $2.05 \pm 0.14^{*}$ & $0.62 \pm 0.1$ & $0.52 \pm 0.0$ & BDL \\
Vanillin & BDL & BDL & $146 \pm 0.01^{* *}$ & $3.04 \pm 0.0$ \\
Syringic acid & $12.83 \pm 0.34$ & BDL & BDL & BDL \\
Total & 58.5 & 16.7 & 294.1 & 264.2 \\
\hline
\end{tabular}

\section{Discussion}

\section{Soluble sugars}

Accumulation of non-volatile compounds like soluble sugars in the fruit bodies of mushrooms and their organoleptic qualities (e.g. sweetness) are dependent on the soluble sugars (Litchfield 1967, Barros et al. 2007, Jedidi et al. 2016, Ravikrishnan et al. 2021). The type and quantity of soluble sugars varied greatly among the wild edible mushrooms of the Western Ghats (Ravikrishnan et al. 2021). Soluble sugars, as well as their quantities, differed among the uncooked and cooked mushrooms Amanita sp. as well as Astraeus hygrometricus in the present study, compared with another edible ectomycorrhizal mushroom Amanita hemibapha of the Western Ghats (Ravikrishnan et al. 2021). Amanita sp. was devoid of maltose and possibly broken into glucose during drying or processing (Barros et al. 2008). However, the maltose content was significantly higher in uncooked A. hygrometricus might have not been affected by the methods of processing followed. Galactose was below the detectable level in Amanita sp., while in Astraeus hygrometricus, it was as high as $2.5-9.5 \mathrm{mg} / \mathrm{g}$. Similarly, Astraeus hygrometricus was devoid of trehalose, while it was as high as $8.8-9.2 \mathrm{mg} / \mathrm{g}$ in Amanita sp. Trehalose constitutes one of the principal carbohydrates in both European wild mushrooms as well as cultivated mushrooms in China (Kalač 2009, Li et al. 2014). Its content was drastically higher in Amanita sp. compared to Amanita hemibapha as well as Amanita porphyria (Reis et al. 2011, Ravikrishnan et al. 2021). Trehalose has several industrial applications, as it is useful in food industries as a food additive to increase sweetness and to promote freeze-dry preservation (Gibney et al. 2015). Sugar content in wild mushrooms seems to be dependent on various factors, like developmental stages, harvest conditions, and genetic makeup (Turfan et al.2018). Since, the cultivated mushrooms have mostly uniform substrate as well as growth parameters (e.g. temperature, $\mathrm{pH}$, conductivity, and O- $\mathrm{R}$ potential), the product composition may not vary too much. Hence, there is a scope to maneuver the substrates and conditions to fine-tune the soluble sugars in cultivated mushrooms favorably. However, such possibilities need further insight for those ectomycorrhizal mushrooms that produce mycelia or fruit bodies on composted agro-wastes.

\section{Organic acids}

Besides playing the main role in taste as well as flavour, they serve as antioxidants, antiinflammatory, neuroprotective, and antimicrobial traits necessary for human health protection (Altmeyer et al. 1994, Valentão et al. 2005b, Seabra et al. 2006, Ribeiro et al. 2008, Brennan et al. 
2000, Leal et al. 2013, Gąsecka et al. 2018). Gąsecka et al. (2018) reported a variety of organic acids in the wild as well as cultivated edible Agaricus spp. There is a drastic variation in the quantities of different organic acids between the mushrooms (Amanita sp. and Astraeus hygrometricus) as well as processing methods (uncooked and pressure-cooked) in our study. Such variations also reported in six wild edible mushrooms from the foothills of the Western Ghats (Ravikrishnan et al. 2021). According to Cámara et al. (1994), the organic acids not affected by the methods of processing and storage in foodstuffs like fruit juice and nectar. In our study, the succinic acid content in Astraeus hygrometricus was significantly increased on pressure-cooking, while it was the opposite for tartaric as well as ascorbic acids. However, pressure-cooking of Amanita sp. has drastically knocked off the organic acids (6 vs. 2) as well as their quantities (tartaric and malic acids). Uncooked Amanita sp. has a similar quantity of ascorbic acid, lower in citric acid, and higher succinic and malic acids compared to Amanita rubescens (Kouassi et al. 2016). Uncooked Amanita sp. has more quantity of organic acids compared with another edible ectomycorrhizal mushroom Amanita hemibapha of the Western Ghats (6 vs. 3) (Ravikrishnan et al. 2021). The A. hemibapha had lactic acid in addition to ascorbic and succinic acids. Similar to Amanita caesarea in Portugal, uncooked Amanita sp. in our study possesses citric as well as malic acids (Valentão et al. 2005b). Succinic acid serves as a precursor to many industrially important chemical compounds like adipic acid, 1,4butanediol, tetrahydrofuran, $\mathrm{N}$-methyl pyrrolidinone, 2-pyrrolidinone, succinate salts, and gammabutyrolactone (Song and Lee, 2006). The mega doses of ascorbic acid (vitamin C) used to prevent many human ailments like diabetes, cataracts, glaucoma, macular degeneration, atherosclerosis, stroke, heart disease and cancer (Iqbal et al. 2004). In addition, the organic acids are capable of improving shelf life as well as preventing bacterial spoilage (Ouattara et al. 1997, Singla et al. 2012).

\section{Polyphenols}

In addition to fruits and vegetables, mushrooms possess several polyphenols (Barros et al. 2009). Interest in mushroom polyphenols is increasing recently owing to their therapeutic as well as nutraceutical potential (e.g. radical scavenging, metal chelation, and inhibition of lipid oxidation) (Cheung et al. 2003, Yoon et al. 2011). Gąsecka et al. $(2016,2018)$ have reported a variety of polyphenols in wild as well as cultivated edible Agaricus spp. as well as Pleurotus spp., and related their antioxidant potential to serve as nutraceuticals. Many studies have interrelated the antioxidant capacity of mushrooms with polyphenols (e.g. Ren et al. 2014, Lin et al. 2015, Smolskaité et al. 2015). In most instances, pressure-cooking of Amanita sp. and Astraeus hygrometricus reduced or knocked off the organic acids. However, in A. hygrometricus, gallic acid, methyl catechol, and epicatechin were below detectable limits in uncooked samples but showed up in cooked samples with an extremely high quantity of epicatechin $(220 \mu \mathrm{g} / \mathrm{g})$. When compared to Amanita sp., Astraeus hygrometricus had higher concentrations of myricetin and ethyl catechol. Myricetin has gained recognition for its nutraceutical value owing to its antioxidant, anticancer, antidiabetic, and anti-inflammatory activities (Semwal et al. 2016). The p-coumaric acid protects the liver and kidney against CIS-induced oxidative damage in experimental animal models, and it inhibits oxidative stress (Akdemir et al. 2017).

\section{Conclusion}

The composition of the edible mushrooms is dependent on the habitat, substrate, and growth stage. Amanita sp. as well as Astraeus hygrometricus assessed in this study are ectomycorrhizal and ethnically edible mushrooms in the early stage of development of the fruit body. They are easily available in the coastal belts of the southwest and the foothills of the Western Ghats of India, which provide food and economic security to the local people and tribal people during the rainy season. The profiles of soluble sugars, organic acids, and polyphenols shed light on the nutraceutical value of these mushrooms. Furthermore, studies on their proximal, mineral, amino acids, fatty acids, functional properties, and antioxidant potential show that they are superior in terms of the nutritional value as well as health-promoting potential. In the comparison of these mushrooms, the 
total organic acids were highest in cooked A. hygrometricus, so also the total polyphenols in uncooked as well as cooked A. hygrometricus. Similarly, cooked Amanita sp. possesses a good quantity of trehalose, gallic acid, and ethyl catechol. The novelty of these mushrooms will allow them to employ in the production of attractive diets as well as health-promoting diets and valueadded functional foods. There is a strong link between these mushrooms as ectomycorrhizas in many tree species, especially Anacardium occidentale, Artocarpus hirsutus, Holigarna arnottiana, Hopea parviflora, H. ponga, Phyllanthus emblica, Syzygium cumini, and Terminalia paniculata. The future concern is to protect these trees to conserve Amanita sp. as well as Astraeus hygrometricus for the benefit of human nutrition and health.

\section{Acknowledgement}

Department of Science and Technology, New Delhi financed this research by the award of DST-INSPIRE fellowship to Greeshma AA. Authors acknowledge technical help rendered by Dr. Mahadevakumar, Department of Botany, University of Mysore, Mysore (India). We are thankful to the reviewers for constructive suggestions and comments to improve the manuscript substantially. The authors declare that there are no conflict of interest to publish this article in Fungal Biotec.

\section{References}

Akdemir EFN, Albayrak M, Çalik M, Bayir Y, Gülçin İ. 2017 - The protective effects of pcoumaric acid on acute liver and kidney damages induced by cisplatin. Biomedicines 5, 18, 10.3390/biomedicines5020018

Altmeyer PJ, Mattlies U, Pawlak F, Hoffmann K, Frosch PJ et al. 1994 - Antipsoriatic effect of fumaric acid derivatives results of a multicenter double-blind study in 100 patients. Journal of the American Academy of Dermatology 30, 977-981.

Barros L, Baptista P, Correia DM, Casal S, Oliveira B et al. 2007 - Fatty acid and sugar compositions and nutritional value of five wild edible mushrooms from northeast Portugal. Food Chemistry 105, 140-145.

Barros L, Cruz T, Baptista P, Estevinho LM, Ferreira ICFR et al. 2008 - Wild and commercial mushrooms as source of nutrients and nutraceuticals. Food Chemistry and Toxicology 46, 2742-2747.

Barros L, Dueñas M, Ferreira ICFR. 2009 - Phenolic acids determination by HPLC-DAD-ESI/MS in sixteen different Portuguese wild mushrooms species. Food Chemistry and Toxicology 47, 1076-1079.

Barros L, Pereira C, Ferreira ICFR. 2013 - Optimised analysis of organic acids in edible mushrooms from Portugal by ultrafast liquid chromatography and photodiode array detection. Food Analytical Methods 6, 309-316.

Boa E. 2004 - Wild edible fungi. A global overview of their uses and importance.FAO, Rome, http //www.fao.org/docrep/007/y5489e/y5489e00.htm (Accessed on July 3, 2021)

Boa E. 2012 - Local Communities and Edible Ectomycorrhizal Mushrooms. In: Edible Ectomycorrhizal Mushrooms. Springer-Verlag, Berlin, Pp. 307-315.

Brennan M, Le Port G, Gormley R. 2000 - Post-harvest treatment with citric acid or hydrogen peroxide to extend the shelf life of fresh sliced mushrooms. LWT Food Science and Technology 33, 285-289.

Cámara M, Díez C, Torija ME, Cano MP. 1994 - HPLC determination of organic acids in pineapple juices and nectars. Zeitschrift für Lebensmittel-Untersuchung und Forschung 198, $52-56$.

Chang ST, Wasser SP. 2012 - The role of culinary-medicinal mushrooms on human welfare with a pyramid model for human health. International Journal of Medicinal Mushrooms 14, 95-134.

Cheung LM, Cheung PC, Ooi VE. 2003 - Antioxidant activity and total phenolics of edible mushroom extracts. Food chemistry 81, 249-255. 
Cheung PC. 2010 - The nutritional and health benefits of mushrooms. Nutrition Bulletin 35, 292299.

Farook VA, Khan SS, Manimohan P. 2013 - A checklist of agarics (gilled mushrooms) of Kerala state, India. Mycosphere 4, 97-131.

Gąsecka M, Magdziak Z, Siwulski M, Mleczek M. 2018 - Profile of phenolic and organic acids, antioxidant properties and ergosterol content in cultivated and wild growing species of Agaricus. European Food Research and Technology 244, 259-268.

Gąsecka M, Magdziak Z, Siwulski M, Niedzielski P. 2016 - Phenolic composition and antioxidant properties of Pleurotus ostreatus and Pleurotus eryngii enriched with selenium and zinc. Eur Food Res Technol 242, 723-732.

Gibney PA, Schieler A, Chen JC, Rabinowitz JD, Botstein D. 2015 - Characterizing the in vivo role of trehalose in Saccharomyces cerevisiae using the AGT1 transporter. Proceedings of the National Academy of Sciences 112, 6116-6121.

Greeshma AA, Sridhar KR, Pavithra M. 2018a - Nutritional perspectives of an ectomycorrhizal edible mushroom Amanita of the southwestern India. Current Research in Environmental \& Applied Mycology 8, 54-68.

Greeshma AA, Sridhar KR, Pavithra M. 2018b - Functional attributes of ethnically edible ectomycorrhizal wild mushroom Amanita in India. Microbial Biosystems 3, 34-44.

Greeshma AA, Sridhar KR, Pavithra M, Tomita-Yokotani K. 2018c - Bioactive potential of nonconventional edible wild mushroom Amanita. In Fungi and their Role in Sustainable Development Current Perspectives, Gehlot P, Singh J (Ed). Springer Nature, Singapore, Pp. 719-738.

Hall IR, Lyon T, Yun, W, Buchanan P. 2011 - A list of putative edible or medicinal ectomycorrhizal mushrooms. http//www.trufflesandmushrooms.co.nz, 10.13140/RG.2.1.2978.9048 (accessed July 23, 2021).

Hall IR, Yun W, Amicucci A. 2003 - Cultivation of edible ectomycorrhizal mushrooms. Trends in Biotechnology 21, 433-438.

Hobbs C. 2000 - Medicinal values of Lentinus edodes (Berk.) Sing. (Agaricomycetideae). A literature review. International Journal of Medicinal Mushrooms 2, 287-297.

Hyde KD, Xu J, Rapior S, Jeewon R, Lumyong S et al. 2019 - The amazing potential of fungi 50 ways we can exploit fungi industrially. Fungal Diversity 97, 1-136, https//doi.org/10.1007/s13225-019-00430-9

Iqbal K, Khan A, Khattak MMAK. 2004 - Biological significance of ascorbic acid (Vitamin C) in human health-a review. Pakistan Journal of Nutrition 3, 5-13.

Jedidi IK, Ayoub IK, Philipe T, Bouzouita N. 2016 - Chemical composition and non-volatile components of three wild edible mushrooms collected from northwest Tunisia. Mediterranean Journal of Chemistry 5, 434-441.

Kalač P. 2009 - Chemical composition and nutritional value of European species of wild growing mushrooms - A review. Food Chemistry 113, 9-16.

Karun NC, Sridhar KR. 2013 - Occurrence and distribution of Termitomyces (Basidiomycota, Agaricales) in the Western Ghats and on the west coast of India. Czech Mycology 65, 233254.

Karun NC, Sridhar KR. 2014 - A preliminary study on macrofungal diversity in an arboretum and three plantations of the southwest coast of India. Current Research in Environmental \& Applied Mycology 4, 173-187.

Karun NC, Sridhar KR. 2016 - Spatial and temporal diversity of macrofungi in the Western Ghat forests of India. Applied Ecology and Environmental Research 14, 1-21.

Karun NC, Sridhar KR. 2017 - Edible wild mushrooms in the Western Ghats data on the ethnic knowledge. Data in Brief 14, 320-328. 
Kouassi KA, Kouadio EJP, Konan KH, Dué AE, Kouamé LP. 2016 - Phenolic compounds, organic acid and antioxidant activity of Lactarius subsericatus, Cantharellus platyphyllus and Amanita rubescens, three edible ectomycorrhizal mushrooms from center of Côte d'Ivoire. Eurasian Journal of Analytical Chemistry 11, 127-139.

Latha KPD, Manimohan P. 2017 - Inocybes of Kerala. SporePrint Books, Calicut, Kerala, India.

Leal AR, Barros L, Barreira JC, Sousa MJ, Martins A et al. 2013 - Portuguese wild mushrooms at the "pharma-nutrition" interface Nutritional characterization and antioxidant properties. Food research international 50, 1-9.

Li W, Gu Z, Yang Y, Zhou S, Liu Y, Ahang J. 2014 - Non-volatile taste components of several cultivated mushrooms. Food Chemistry 143, 427-431.

Lin S, Ching L.T, Chen J, Cheung PCK. 2015 - Antioxidant and anti-angiogenic effects of mushroom phenolics-rich fractions. Journal of Functional Foods 17, 802-815.

Litchfield JH. 1967 - Morel mushroom mycelium as a food-flavouring material. Biotech. Bioeng 9, 289-304.

Ouattara BO. Simard RE, Holley RA, Piette, G.J-P, Bégin A. 1997 - Inhibitory effect of organic acids upon meat spoilage bacteria. Food Protection 60, 246-253.

Pavithra M, Greeshma AA, Karun NC, Sridhar KR. 2015 - Observations on the Astraeus spp. of Southwestern India. Mycosphere 6, 421-432.

Pavithra M, Sridhar KR, Greeshma AA, Karun NC. 2016a-Spatial and temporal heterogeneity of macrofungi in the protected forests of Southern India. Journal of Agricultural Technology 12, $105-124$.

Pavithra M, Sridhar K.R, Greeshma AA, Tomita-Yokotani K. 2016b - Bioactive potential of the wild mushroom Astraeus hygrometricus in South-west India. Mycology 7, 191-202.

Pavithra M, Sridhar KR, Greeshma AA. 2017 - Functional properties of edible mushroom Astraeus hygrometricus. KAVAKA - Transactions of the Mycological Society of India 49, 22-27.

Pavithra M, Sridhar KR, Greeshma AA. 2018 - Nutritional quality attributes of edible gasteroid wild mushroom Astraeus hygrometricus. In: Fungi and their Role in Sustainable Development Current Perspectives. Gehlot P, Singh J (Ed). Springer Nature, Singapore, Pp. 367-382.

Pérez-Moreno J, Martínez-Reyes M. 2014 - Edible ectomycorrhizal mushrooms biofactories for sustainable development. In: Biosystems Engineering Biofactories for Food Production in the Century XXI. Springer International, Pp. 151-233.

Ravikrishnan V, Sridhar KR, Rajashekhar M. 2021 - Bioactive attributes of edible wild mushrooms of the Western Ghats. In: Advances in Macrofungi Pharmaceuticals and Cosmeceuticals. Sridhar KR, Deshmukh SK (Ed). CRC Press, Taylor \& Francis, Boca Raton, Pp. 20-38.

Reis FS, Pereira E, Barros L, Sousa MJ et al. 2011 - Biomolecule profiles in inedible wild mushrooms with antioxidant value. Molecules 16, 4328-4338.

Ren L, Hemar Y, Perera CO, Lewis, G, Krissansen GW, Buchanan PK. 2014 - Antibacterial and antioxidant activities of aqueous extracts of eight mushrooms. Bioactive Carbohydrates and Dietary Fibre 3, 41-51.

Ribeiro B, Andrade PB, Baptista P, Barros L, Ferreira IC et al. 2008 - Leucopaxillus giganteus mycelium effect of nitrogen source on organic acids and alkaloids. Journal of Agricultural and Food Chemistry 56, 4769-4774.

Seabra RM, Andrade PB, Valentão P, Fernandes E et al. 2006 - Anti-oxidant compounds extracted from several plant materials. In: Biomaterials from Aquatic and Terrestrial Organisms. First Edition, CRC Press, Pp. 115-174.

Semwal DK, Semwal RB, Combrinck S, Viljoen A. 2016 - Myricetin A dietary molecule with diverse biological activities. Nutrients 8, 90, 10.3390/nu8020090

Senthilarasu G. 2014 - Diversity of agarics (gilled mushrooms) of Maharashtra, India. Current Research in Environmental \& Applied Mycology 4, 58-78. 
Senthilarasu G, Kumaresan V. 2016 - Diversity of agaric mycota of Western Ghats of Karnataka, India. Current Research in Environmental \& Applied Mycology 6, 75-101.

Singla R, Ganguli A, Ghose M. 2012 - Physicochemical and nutritional characteristics of organic acid-treated button mushrooms (Agaricus bisporus). Food and Bioprocess Technology 5, 808-815.

Smolskaité L. Venskutonis PR, Talou T. 2015 - Comprehensive evaluation of antioxidant and antimicrobial properties of different mushroom species. LWT Food Science and Technology $60,462-471$.

Song H, Lee SY. 2006 - Production of succinic acid by bacterial fermentation. Enzyme and Microbial Technology 39, Pp. 352-361.

Sridhar KR, Karun NC. 2019 - Diversity and ecology of ectomycorrhizal fungi in the Western Ghats. In: Microbial Interventions in Agriculture and Environment - Research Trends, Priorities and Prospects. Volume 1, Singh DP, Gupta VK, Prabha R (Ed), Springer Nature, Pp. 479-507.

StatSoft Inc. 2008 - Statistica, Version \# 8, StatSoft, Tulsa, Oklahoma.

Turfan N, Pekşen A, Kibar B, Ünal S. 2018 - Determination of nutritional and bioactive properties in some selected wild growing and cultivated mushrooms from Turkey. Acta Scientiarum Polonorum Horticulture 17, 27-72.

Valentão P, Andrade PB, Rangel J, Ribeiro B, Silva BM et al. 2005a - Effect of the conservation procedure on the contents of phenolic compounds and organic acids in chanterelle (Cantharellus cibarius) mushroom. Journal of Agricultural and Food Chemistry 53, 4925-4931.

Valentão P, Lopes G, Valente M, Barbosa P, Andrade PB et al. 2005b - Quantitation of nine organic acids in wild mushrooms. Journal of Agricultural and Food Chemistry 53, 36263630.

Yoon KN, Alam N, Lee KR, Shin PG, Cheong JC et al. 2011 - Antioxidant and antityrosinase activities of various extracts from the fruiting bodies of Lentinus lepideus. Molecules 16, 2334-2347.

Zambonelli A, Bonito GM. 2012 - Edible Ectomycorrhizal Mushrooms. Current Knowledge and Future Prospects. Springer-Verlag, Berlin Heidelberg, Pp. 409. 